\title{
The Lausanne Trilogue Play within the outcome evaluation in infant mental health: a preliminary report
}

\author{
Michela Gatta, ${ }^{1}$ Marta Sisti, ${ }^{1}$ Laura Sudati, ${ }^{1}$ Marina Miscioscia, ${ }^{2}$ Alessandra Simonelli ${ }^{3}$ \\ ${ }^{1}$ Infancy, Adolescence and Family Service, Local Health Unit 16 of Padua, Padua, Italy; ${ }^{2}$ Department of Psychology and Clinics of \\ Human Systems, University of Liège, Liège, Belgium; ${ }^{3}$ Department of Developmental and Socialization Psychology, University of \\ Padua, Padua, Italy
}

\begin{abstract}
This study aims to contribute to the scientific debate about the evaluation of the intervention in infant mental health and presents the main results after one year of intervention based on integrated types of treatments (psychodynamic psychotherapy for the child/adolescent, parental support and observation and assessment of family interactions). Furthermore, the study aims to explore the use of the Lausanne Trilogue Play (LTP) as a new assessment tool for planning the of treatments. The sample consists of 23 children and adolescents, aged between 4 and 17 years old, and their families, attending the Infancy, Adolescence and Family Service, Local Health Unit 16 of Padua due to their psychopathological problems. In order to assess their psychological conditions we used the Child Behavior Checklist (CBCL) to evaluate psycho-behavioral problems and the LTP to assess family interactions. The CBCL was used at the time of the diagnostic assessment (T0) and after 12 months of treatment (T12). Concerning the application of LTP, the sample was divided randomly in two groups: one where LTP was used in two different time intervals during therapy (T0 and T12) and another one where it was used in three different time intervals during therapy (T0, T6 and T12) with a video-feedback intervention at time T6. Results report a favorable outcome in regards of the gravity of patients' symptoms, displaying, after one year of treatment, a statistical significant decrease in the clinical level of internalizing symptoms. In terms of family interactions, results show stability within the family patterns except for a statistically significant deterioration in the management of interactive mistakes. Regarding the use of LTP as evaluator of the above intervention, the study shows that the assessment of family's interactions during long-term psychotherapy helps clinicians focus the intervention on those aspects that remain dysfunctional. These results and the possible interpretations, however, emphasize the need for further studies on this topic.
\end{abstract}

Key words: Lausanne Trilogue Play; Infant mental health; Clinical treatment effectiveness; Integrated treatment; Video feedback intervention.

Correspondence: Michela Gatta, Infancy, Adolescence and Family Service, Local Health Unit 16 of Padua, via Dei Colli, 4, 35143 Padua, Italy.

Tel: +39.049 .8217690 .

E-mail: michela.gatta@unipd.it

Acknowledgments: the broader research project called The Lausanne Trilogue Play used as psycho-diagnostic and therapeutic tool in a Neuropsychiatric Unit: an innovative clinical experience working with psychiatric children and adolescents began in 2012 and it was funded by the Italian Ministry of Health (GR-20102318865). We thank Helen Kingsley and Manuela Di Fronzo for the help in the English translation.

Citation: Gatta, M., Sisti, M., Sudati, L., Miscioscia, M., \& Simonelli, A. (2016). The Lausanne Trilogue Play within the treatments' effectiveness evaluation in infant mental health: a preliminary report. Research in Psychotherapy: Psychopathology, Process and Outcome, 19(1), 19-30. doi: 10.4081/ripppo.2016.198

Received for publication: 15 September 2015.

Revision received: 18 January 2016.

Accepted for publication: 18 January 2016

This work is licensed under a Creative Commons Attribution NonCommercial 4.0 License (CC BY-NC 4.0).

(C) Copyright M. Gatta et al., 2016

Licensee PAGEPress, Italy

Research in Psychotherapy:

Psychopathology, Process and Outcome 2016; 19:19-30

doi:10.4081/ripppo.2016.198

\section{Introduction}

This study is part of a broader research project that began in 2012 and was based on the cooperation between the Infancy, Adolescence and Family Service, Local Health Unit 16 and the Department of Developmental Psychology and Socialization (DPSS) of the University of Padua. The main goal of this project was to assess the value of the Lausanne Trilogue Play paradigm (LTP; Fivaz-Depeursinge \& Corboz-Warnery, 1999) in the diagnostic workup and treatment of families with children or adolescents revealing individual and/or familiar psychological problems (Simonelli et al., 2014; Gatta et al., 2015a, 2015c).

Our preliminary data on a sample of 151 children and adolescents confirmed a link between psychological disorders in developmental age and family dynamics although this relationship does not appear to be linear (Gatta, Simonelli, Svanellini, Sisti, \& Sudati, in press-a; Gatta et al., in press-b). However, what seems to be confirmed from our data is that adolescents with internalizing problems, somatic complaints and attention difficulties belong to families with high levels of conflict between parents (Gatta et al., 2015a). In addition, in a case control study run in 2015 on the transmission of the parent-ado- 
lescent attachment bond (Gatta et al., 2015b) results confirmed the prevalence of dysfunctional parental attachment bonds in adolescents with psychopathological issues, stressing the important role of interactive family patterns as risk or protective factors for the onset of psychiatric disorders.

Overall, our preliminary results underline the role of the relational environment in developmental psychopathology and the need to consider the parental couple within the process of taking care of children and adolescents with psychopathological problems. All these findings are in line with recent international researches and theoretical developments that show how involving parents is no longer exclusively necessary in the work with children but also with adolescents, despite the various peculiarities of such developmental stage (Aliprandi, Pelanda \& Senise, 1990; Losso, 2000; Vallino, 2009). Actually, thirty years ago the attention to parents in the perspective of a psychotherapeutic treatment with children and adolescents was limited to the diagnostic assessment and there was almost no involvement during treatment, the latter focused exclusively on children/adolescents; nowadays, instead, the understanding and the treatment of mental disease would depend specifically on the suffering relationship, with the aim to adjust it (Novick \& Novick, 2009). Specifically in adolescence, parenting support helps to give new meanings to the discomfort of the adolescent in order to facilitate the identification of functional communication skills, new interpersonal patterns and to support the working alliance (Bonfiglio, 2009). However, this important theoretical and technical transformation within psychotherapeutic interventions with children and adolescent does not always correspond to a real change in clinical practice. For these reasons, it seems to be increasingly important to carry out studies, which evaluate the use of an integrated approach and broaden the debate about the most effective methods of intervention with parents.

For all these considerations, in this study we decided to focus on the assessment of the clinical effectiveness of integrated treatment in infant mental health characterized by psychotherapy for the child/adolescent and parental support for the parents, both carried out in line with the principles of psychodynamic psychotherapy, and by the observation and assessment of family interactions.

In fact, considering the high rate of incidence of psychopathology in developmental age and according to the literature and international guidelines in infant mental health, it is becoming increasingly important to explore the theme of evaluation of treatment in order to understand what the most effective method of intervention (De Coro et al., 2010; Palmer, Nascimento \& Fonagy, 2013; Leichsenring, Leweke, Klein \& Steinert, 2015). In the last ten years we have seen a rapid increase of studies that deal with the effectiveness of the assessment in the context of interventions run during adulthood (Dazzi, 2006; Midgley \& Kennedy, 2011; Lenzo, Gargano, Mucciardi, Lo Verso
\& Quattropani, 2014) while there are few similar studies focusing on developmental age (Palmer et al., 2013).

Two meta-analysis conducted by Midgley and Kennedy (2011) and Palmer et al. (2013) show evidence for the use of psychodynamic psychotherapy for children and adolescents, although these studies generally involve a limited number of participants and relate only to the presence of symptoms, without any assessment of the relational dimension. These meta-analyses show that patients with internalizing disorders seem to respond better to psychotherapeutic treatment than those with externalizing disorders: furthermore, it seems more difficult to involve patients with externalizing problems in research studies and to build a working alliance with them (Midgley \& Kennedy, 2011). Moreover, also in this work, the authors stressed the importance of involving the parental support into child/adolescent's psychotherapy, underlining once again the importance of considering the relational context (Midgley \& Kennedy, 2011; Palmer et al., 2013).

In this perspective, it seems interesting a meta-analysis of 24 studies conducted by Thomas and Zimmer-Gembeck (2007) that evaluated and compared the outcomes of two widely disseminated parent-child interventions called Parent-Child Interaction Therapy (PCIT) and Triple P-Positive Parenting Program (Triple P) on a sample of 3 to 12 years old and their parents. The results showed positive effects of both interventions but the effects depended ultimately on the length of the intervention, on the components and the source of outcome data. However, what seems to be confirmed is that both interventions reduced parent-reported child maladaptive behavior and parenting problems.

Papousek and Chuquisengo (2006) developed an innovative contribution to this issue by proposing a specific model of intervention with the parental couple. Their clinical and empirical study consists on a treatment specifically designed for the developmental problems and psychological needs of infants and their parents. Authors illustrate the diagnostic and therapeutic procedure with an age-specific regulatory disorder in the context of severely distressed primary relationship. Furthermore, the study shows that the method of video-microanalysis during video-feedback with the parents proved particularly efficient thanks to the observation of brief episodes of recorded parent-infant interactions. Concerning this innovative technique, it seems important to underline that other authors are studying the applicability of video-feedback. Several studies (Sameroff, McDonough \& Rosenblum, 2004) have shown the benefits of this kind of intervention. First of all, this technique enables parents to identify any discrepancies between what they think about their parenting skills and what they really have. After all, as stated by Gaggero and Orsini (2002), the active involvement of parents appears to be the factor that most influences the results of therapy.

Continuing to analyze the scientific literature about 
the evaluation of interventions, Odhammar, Sundin, Jonson and Carlberg (2011) conducted a naturalistic study with 33 children and their families who turned to public mental health from 5 cities of Sweden and Denmark. Individuals under the age of 10 followed a psychodynamic psychotherapy with one or two sessions a week for a period of between six months and two and a half years; parents followed a weekly or fortnightly psychotherapy; every three/six months both parents and therapists completed questionnaires on the overall functioning of the child respectively (CGAS and HCAM) (Shaffer et al., 1983, 1996). The research results show significant improvement detected with both questionnaires used in the overall functioning of the child as a result of psychotherapy and the parallel work with parents.

A randomized controlled trial conducted by Jacobsen, McKinney and Holck (2014) investigated the effect of music therapy on the observed interaction between the parents and child and showed that dyads that received music therapy intervention significantly improved their interaction and mutual attunement. Furthermore, parents who participated in the intervention reported themselves to be significantly less stressed by the child's behavior and to significantly improve their parent-child relationship.

With specific attention to the externalizing problems, Hemphill and Littlefield (2006) investigated the characteristics of 106 children, primarily referred for externalizing behavior problems, and their family. The authors assessed the prediction of treatment outcome following a standardized short-term, cognitive behavioral group program. The results show that the main predictors of reductions in externalizing and internalizing behaviors following treatment were children's pre-existing levels of the above behavioral and emotional problems and positive parent-child interaction.

As confirmed by a longitudinal study conducted by Trautmann-Villalba, Gschwendt, Schmidt and Laucht (2006), father's and infant's interaction were related to children's externalizing behavioral problems. This study was conducted on a sample of children aged between 8 and 11 and it suggests that the quality of father-child interactions during early infancy may predict later behavioral problems at school age, although further studies are needed.

The role of working with the parental couple is observed not only in the clinical context but also in preventive interventions aimed to avert the development of psychopathology in childhood: in a randomized trial lasted ten years, Cowan, Cowan and Barry (2011) analyzed two variations of groupal preventive intervention offered to parental couples in the year before their oldest child made the transition to kindergarten. The paper showed interesting results: the variations of the intervention produced positive outcomes on parent-child relationship, on children's adaptation to kindergarten and on couples' interactions.

Ultimately, empirical and clinical evidence showed that interactions within the family are predictive of several outcomes in children. Healthy development is most likely to occur in the context of high levels of warmth and acceptance and consistent behavioral control in parent-child interactions; conversely, conflictual or disorganized interactive practices in the family, with predominantly negative affect and harsh and distant parenting, are predictive of maladaptive or even psychopathological socio-emotional development (Fauber \& Long, 1991; Cummings, Davies \& Campbell, 2000; McHale, 2007).

As can be seen, the relational perspective is the current clinical-theoretical horizon of recent research dealing with developmental psychopathology. According to this, FivazDepeursinge and Corboz-Warnery (1999) developed the LTP, which aims to study the interaction of the triadic family consisting of mother, father and child.

There are several works that applied this methodology and found good psychometric characteristics of the coding system proposed by the authors (Carneiro, Corboz-Warnery \& Fivaz-Depeursinge, 2006) also in different cultural contexts (Simonelli, Fava Viziello, Bighin, De Palo \& Petech, 2007). Several studies confirmed the value of LTP, both as a tool for identifying the features of triadic interactive competences in early infancy and as a method for screening children from early infancy to preschool age in terms of their emotional-relational outcomes (Favez et al., 2006; Simonelli, Bighin \& De Palo, 2012; Simonelli et al., 2014; Gatta et al., 2015a, in press-a, in press-b). Studies using LTP to analyze the developmental trajectories of triadic interactive competences from pregnancy to the early years of a child's life, with a view to identifying patterns of stability and/or change characterizing this developmental process, showed that the quality of the interactions between mother, father and child remain generally stable during the first 18 months of the child's life (Favez et al., 2006; Simonelli et al., 2012; Hedenbro \& Rydelius, 2013). This stability seems to be a sort of prerequisite that enables the triadic interactive system to be considered as a primary relational matrix in which children can express and consolidate their emerging competences thanks to the repeatability and predictability of their interactive exchanges. Other studies (Bighin, De Palo \& Simonelli, 2011) identified a dynamic, non-linear developmental path in two distinct but continuous stages. The first stage, when the child is between four and nine months old, is characterized by a relative instability and a tendency to change and sharpen up the competences at work in the interactive and affective exchange within the family system. The second stage, from nine months to four years of age, seems to be characterized, instead, by a consolidation of the previously acquired interactive competences.

As for research on the application of the LTP in preschool age, several studies conducted on both clinical and non-clinical populations demonstrated a general decline in the quality of the triadic interactions during the course of the LTP procedure, with significantly lower scores being 
achieved in the fourth part of the procedure (Petech, Simonelli \& Altoè, 2009; Simonelli, Fava Viziello, Petech, Ballabio \& Bisoni, 2009; Hedenbro \& Rydelius, 2013).

Despite the numerous studies that confirm the value of LTP as a tool for identifying the features of triadic interactive competences, few studies have investigated the use of this instrument in a clinical setting (Ballabio \& Sala, 2012; Mazzoni, Castellina \& Veronesi, 2012; Gatta et al., 2014; Simonelli et al., 2014; Svanellini et al., in press).

This study will present the results of one-year pilot research, which evaluated the clinical effectiveness of integrated treatment characterized by a long-term psychotherapy for child/adolescent and parental support for the parents carried out by psychodynamic psychotherapists in a public Mental Health Service. The effectiveness was measured by the Child Behavioral Check List (CBCL; Achenbach \& Rescorla, 2001) that evaluates psychopathological profile. At the same time this study analyzed the family interactions through the LTP (FivazDepeursinge \& Corboz-Warnery, 1999; Favez et al., 2006) in order to: assess the contribution of the LTP as a tool for evaluating the effectiveness of the assessment and of the interventions in infant mental health; observe the trends of family interaction after one year of integrated treatment.

More specifically, this study had three primary aims. The first one was to explore the clinical effectiveness of a long-term integrated treatment for children and adolescents on the psychopathological profile. We hypothesized that a favorable outcome regarded the patient's psychopathological symptoms. In order to test this, we compared psychopathology scores at CBCL at the beginning of the assessment (T0) and after one year of treatment (T12) expecting a change of the clinical profiles towards the normative ones.

The second aim was to explore the value of the LTP as a useful tool for the assessment of interventions in infant mental health and, in particular, to evaluate family interactions during the diagnostic assessment and after one year of integrated treatment. We hypothesized to find changes in the quality of family interactions after one year of integrated treatment. In order to test this, we compared the quality of family dynamics during the diagnostic assessment (T0) and after one year of treatment (T12).

The third aim was to evaluate family interactions, during the diagnostic assessment and after one year of integrated treatment within two specific subgroups, thanks to the use of LTP application. In fact, regarding the application of LTP, the sample was divided randomly in two groups: one where the instrument was used in two different time intervals of the therapy (T0 and T12) and another where the instrument was used in three different time intervals of the therapy (T0, T6 and T12) with a video-feedback intervention at time T6. Specifically, we hypothesized that the use of a video-feedback intervention could modify family interactions assessed after one year (T12).

\section{Methods}

\section{Study design and procedures}

The broader research called The Lausanne Trilogue Play used as psycho-diagnostic and therapeutic tool in the Neuropsychiatric Unit: an innovative clinical experience working with psychiatric children and adolescents (GR-2010-2318865) involved a longitudinal study lasting 36 months. The sample, being recruited at the Infancy, Adolescence and Family Service, Local Health Unit 16 of Padua consisted of patients aged between 3 and 18 years old, and their parents, referred for a psycho-diagnostic assessment due to emotional or behavioral problems. The neuropsychiatric consultation was scheduled with separate diagnostic interviews with the participants and their parents, and it was conducted by a developmental neuro-psychiatrist and a psychodynamic psychotherapist.

In particular, this paper focuses on the effectiveness evaluated after the first year of integrated treatments, characterized by psychodynamic psychotherapy for the child/adolescent, parental support for the parents and the observation and assessment of family interactions.

Upon spontaneous arrival at the Infancy Adolescence Family Unit, participants underwent a diagnostic assessment consisting of: clinical interviews, projective tools (chosen in line with the age-range of the patient), self-report tools and the LTP (Fivaz-Depeursinge \& CorbozWarnery, 1999). After the diagnostic assessment, the families were enrolled and divided in two groups (Groups 1 and 2; Figure 1). For each group child psychotherapy was provided, while there was a distinction in the parental taking in charge. Specifically, group 1 provided weekly psychotherapy for the child while group 2 provided psychotherapy for the child, alongside with fortnightly sessions of parenting support. After this, each group was divided in two further subgroups differing as follows: use of video-feedback every six months (1A and $2 \mathrm{~A}$ ), non-use of video-feedback (1B and 2B).

\section{Participants}

The sample consisted of 23 children and adolescents [average age 12.04; standard deviation (SD) 3.6], 11 of them males (47.8\%) and 12 females $(52.2 \%)$, and their parents (average mothers' age $45.32 ; \mathrm{SD}=5.5$; average age of father 49.86; $\mathrm{SD}=4.9$ ) referred to the Infancy, Adolescence and Family Service, Local Health Unit 16 of Padua. At the beginning the sample was composed from 31 families but after the diagnostic assessment 8 of them dropped out of the research project. Table 1 summarizes the International Classification of Diseases, Tenth Revision, Clinical Modification (ICD-10-CM) Children Diagnosis.

Within the total sample, the families were randomly assigned to one of the two conditions, in particular $\mathrm{n}=7$ families $(30.4 \%)$ were assigned to the condition A (which 
involved the administration of the LTP paradigm every 6 months with video-feedback technique), while $n=16$ families $(69.6 \%)$ were assigned to the condition B (which involved the administration of the LTP paradigm every 12 months without video-feedback technique). Although it was not possible to obtain two sub-groups composed of the same number of subjects because of dropouts, statistical comparisons were possible.

The treatment took place in the public mental health service of Padua and it was characterized by a long-term treatment with weekly 45 minutes sessions for the children/adolescents psychotherapy and by fortnightly 60 minutes sessions for the parenting support. The psychotherapeutic settings of the two different subjects taken into care (children and parents) were kept separate to strengthen the working alliance, in line with current psychodynamic approaches that deal with infancy and adolescence (Aliprandi, Pelanda \& Senise, 1990; Montinari $\&$ Pelanda, 2012).

\section{Tools}

\section{Child Behavior Checklist}

The CBCL (Achenbach \& Rescorla, 2001) is one of the most commonly used scales for rating juvenile behavior, adopted internationally in the clinical setting and in research. It is in the form of a questionnaire (report form) that can be completed by parents (in which case it refers to the last six months of their child's life) or by teachers and/or educators (referring to the situation at the time of the enquiry or to the last two months of the child's life).

The first part of the CBCL comprises 20 items relating to the quality of the child's participation in various activities (sports, at home and at school), and of their relationships with brothers, parents and peers. The second part consists of 118 items that are answered on a threetiered scale $(0=$ not true; $1=$ sometimes true; $2=$ very true $)$. The scores attributed to each item generate two types of profile, one for competences and the other for syndromes. The former profile (competence scales) is obtained from the scores attributed to the 20 items in the first part of the questionnaire and divided into three subscales concerning activities, social functioning, and schooling. The latter psychological and/or psychiatric profile (syndrome scales) derives instead from the scores attributed to the 118 items in the second part of the questionnaire. This second part is divided into three subscales. The first refers to internalizing/externalizing and other problems. The second includes eight syndrome scales that chart a continuum from internalizing to externalizing problems: anxiety and depression; withdrawal; somatic complaints; social problems;

Table 1. International Classification of Diseases, Tenth Revision, Clinical Modification Children Diagnosis.

\begin{tabular}{lcc}
\hline ICD-10-CM diagnosis code & Attendance & Percentage \\
\hline F90-98 & 12 & 52.2 \\
\hline F40-48 & 2 & 8.7 \\
\hline F60-69 & 5 & 21.7 \\
\hline F30-39 & 1 & 4.3 \\
\hline F50-59 & 1 & 4.3 \\
\hline Z55-65 & 1 & 4.3 \\
\hline F80-89 & 1 & 4.3 \\
\hline Total & 23 & 100.0 \\
\hline
\end{tabular}

ICD-10-CM, International Classification of Diseases, Tenth Revision, Clinical Modification.

\begin{tabular}{|c|c|c|c|}
\hline $\begin{array}{l}\text { Spontaneous } \\
\text { request }\end{array}$ & $\begin{array}{l}\text { Psycho-diagnostic assessment } \\
\text { - Self-report questionnaires; } \\
\text { - Interview with clinicians; } \\
\text { - Lausanne Trilogue Play (T0). }\end{array}$ & & \\
\hline \multirow[b]{2}{*}{ Assignment } & $\begin{array}{c}\text { Group l } \\
\begin{array}{c}\text { Taking charge of child/adolescent: weekly sessions (psychotherapy } \\
\text { dynamically oriented) }\end{array}\end{array}$ & & \\
\hline & $\begin{array}{c}\text { Group 2 } \\
\text { Integrated taking charge: } \\
\text { - Weekly sessions child /adolescent (psychotherapy dynamically } \\
\text { oriented) } \\
\text { - Parental support every two weeks }\end{array}$ & & \\
\hline \multicolumn{4}{|c|}{$\begin{array}{cc}\text { Focus of this study } \\
\text { GROUP 2 }\end{array}$} \\
\hline \multirow[t]{2}{*}{$\begin{array}{l}\text { Randomized } \\
\text { subdivision }\end{array}$} & $\begin{array}{c}\text { Group 2A } \\
\text { Psychotherapy + LTP with VF }\end{array}$ & $\begin{array}{c}\text { Repetition of the LTP with VF every } 6 \\
\text { months } \\
\text { (6th, 12th, 18th, 24th) }\end{array}$ & \multirow[t]{2}{*}{$\begin{array}{l}\text { Final follow-up LTP at 36th } \\
\text { months }\end{array}$} \\
\hline & $\begin{array}{c}\text { Group 2B } \\
\text { Only psychotherapy }\end{array}$ & $\begin{array}{l}\text { Repetition of the LTP every } 12 \text { months } \\
\text { (12th and 24th) }\end{array}$ & \\
\hline
\end{tabular}

Figure 1. Design of the research project The Lausanne Trilogue Play used as psychodiagnostic and therapeutic tool in the Neuropsychiatric Unit: an innovative clinical experience working with psychiatric children and adolescents. VF, videofeedback. 
thought-related problems; attention problems; rulebreaking behavior; and aggressive behavior. The third refers to six scales based on the DSM diagnostic categories: affective problems; anxiety problems; somatic problems; attention deficit/hyperactivity problems; oppositional/defiant problems; and behavioral problems. The scores for each scale include reference cut-offs that place a child's symptoms on one of three levels: normal, borderline and clinical. The studies analyzed usually grouped the borderline and clinical levels together (Armsden, Pecora, Payne \& Szatkiewicz, 2000; Bellamy, Gopalan \& Traube, 2010) and, after a preliminary analysis of the distribution of the frequencies for the three levels in our sample, we did so too.

\section{Lausanne Trilogue Play}

The LTP (Fivaz-Depeursinge \& Corboz-Warnery, 1999) is a semi-standardized procedure for observing the quality of the interactions in father-mother-child systems in a situation in which participants play a game together. The activity is divided into four parts corresponding to four triangles that three people interacting with one another can form. In Part I, one of the two parents interact with the child and the other acts simply as a third-party observer (configuration 2+1). In Part II, the parents' roles are reversed so that the parent who previously interacted with the child acts as an observer, while the other parent plays with the child (configuration 2+1). In Part III, both parents interact together with the child; in this case the parents are seated symmetrically in relation to the child and they have the same role (configuration 3). In Part IV, the parents talk together while the child acts as a thirdparty observer (configuration 2+1).

The setting involves two chairs and a highchair suited to the age of the child. The two chairs where the parents sit are placed in relation to the highchair so as to form an equilateral triangle (an arrangement considered ideal for facilitating their interactions).

The procedure for the child was coded according to the FAAS manual (Family Alliance Assessment Scale 6.3; Lavanchy Scaiola, Favez, Tissot \& Frascarolo, 2009); a specific setting for the adolescence age was predisposed (Ballabio, Pantè \& Destro, 2009; Gatta et al., in press-a). These implied two coding approaches, one for the overall procedure and one for each part. Scores were attributed on a three-point Likert scale ( $1=$ inappropriate; $2=$ partially appropriate; $3=$ appropriate; $0=$ if the part was not done) for 14 variables. The variables are grouped into macro-categories: participation (postures and gazes, inclusion of partners), organization (role implication, structure), focalization (coconstruction), affect sharing (parental scaffolding, family warmth, validation, authenticity), timing/synchronization (interactive mistakes during activities, interactive mistakes during transitions) co-parenting (support, conflicts), infant (involvement, self-regulation). Here we present data regarding $14 \mathrm{LTP}$ variables. The variable structure of the ac- tivity is excluded because at the time of the study interval time parameters were undergoing revision work.

The criteria used in attributing the scores were related to the frequency and duration of a given behavior on behalf of the participants during the activity. After viewing the whole video-recording, a global score was assigned to each LTP variable in relation to the activity as a whole. Then each part of the video was watched again and scores were attributed to the variables for each separate part. The sum of the scores attributed to each variable generated three types of total scores: a total for each part of the procedure, obtained from the sum of the scores for the variables within each part; a total for each variable, obtained from the sum of the scores for a given variable (e.g. posture) in all the four parts of the LTP; a total LTP score, obtained from the sum of the subtotals for the four parts (the score can range from 60 to 180). In the present study, the LTP videotapes were coded by two adequately-trained independent judges who achieved an overall consistency calculated using Cohen's kappa of .90.

\section{Results}

With regards to CBCL scores, as Figure 2 shows at the beginning of the treatment, twenty participants' T-score exceeded the cut-off point ( $\mathrm{T}$ score $>65$ ), namely, they were identified as the most serious participants taking part to this study.

In order to test if there were any statistical differences in the level of psychopathology after one year from the taking in charge we performed the McNemar Test. From the results we noticed that, after one year of treatment, there was a statistical significant change $(\mathrm{P}=.031)$ in the clinical level of symptomatology in the area of internalizing problem. Looking at the amount of change between $\mathrm{T} 0$ and T12 we observed a significant decrease from $(\mathrm{M}=68 ; \mathrm{SD}=7.14)$ at $\mathrm{T} 0$, to $(\mathrm{M}=63 ; \mathrm{SD}=8.6)$ at $\mathrm{T} 12$, mean that appears below the cut-off point.

Concerning the quality of family interactions, Tables 2 and 3 show the means of global and sum scores in the 14 variables at $\mathrm{T} 0$ and $\mathrm{T} 12$.

We performed the Lambda of Wilks between the two groups at $\mathrm{T} 0$ that showed no differences $(\Lambda=.230$; $\mathrm{F}=1.339 ; \mathrm{P}=.379)$. Introducing the evaluation of the sociodemographic variables, we did not find any statistical correlation between these variables (average age, presence of siblings, parents' employment, etc.) and the LTP scores.

In order to test if there were any statistical differences between the qualities of family interactive dynamics after one year from the taking in charge we performed a Wilcoxon Test. From the results we noticed no significant differences in the total and sum scores; there was significant difference in two global score of the LTP variables Interactive mistakes and their resolution during activities $(\mathrm{Z}=-2,529 ; \mathrm{P}=.011)$; and Warmth $(\mathrm{Z}=-2.111 ; \mathrm{P}=.035)$, that were not supported by the correction of Bonferroni Post- 
Hoc that, for the present study, required a $\mathrm{P}$ value lower or equal to 0.004 .

Regarding the third aim of this study, we compared the amount of change (increase or decrease) between T0 and T12 comparing the two groups in order to observe if there were any statistical differences due to the videofeedback intervention. We performed a Mann Whitney
Test and from the results we noticed no significant statistical differences between group A and B.

Contrariwise, Table 4 shows significant statistical differences between group A and B in regards to the amount of change in five LTP variables sum scores: Inclusion of the partners, Role implication, Scaffolding, Conflicts, Interactive mistakes during transition.

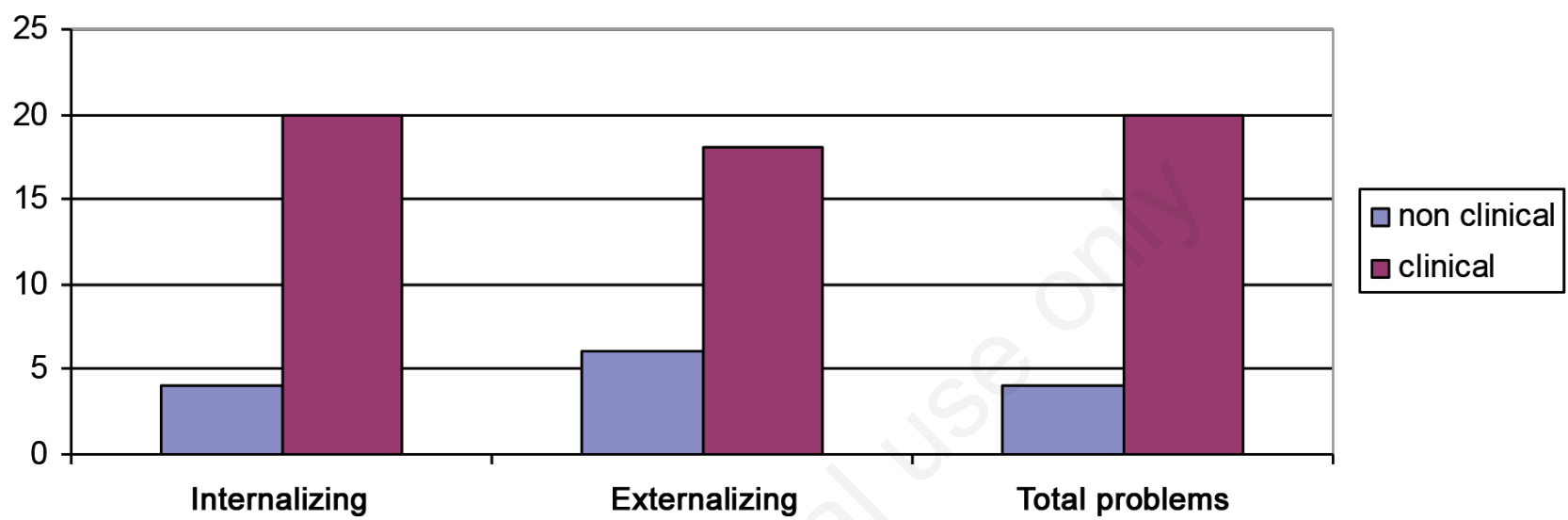

Figure 2. Distribution of Child Behavior Checklist scores $(\mathbf{n}=\mathbf{2 3})$.

Table 2. Mean and standard deviation of the global scores of Lausanne Trilogue Play variables at the time of the diagnostic assessment and after 12 months of treatment divided into group $A(n=7)$ and group $B(n=16)$.

\begin{tabular}{|c|c|c|c|c|c|c|c|c|}
\hline \multirow[t]{3}{*}{ Global score } & \multicolumn{4}{|c|}{ T0 } & \multicolumn{4}{|c|}{ T12 } \\
\hline & \multicolumn{2}{|c|}{ Group A } & \multicolumn{2}{|c|}{ Group B } & \multicolumn{2}{|c|}{ Group A } & \multicolumn{2}{|c|}{ Group B } \\
\hline & Mean & SD & Mean & SD & Mean & SD & Mean & SD \\
\hline Postures and gazes & 1.71 & .488 & 1.88 & .719 & 2.00 & .577 & 1.81 & .655 \\
\hline Inclusion of partners & 2.86 & .378 & 2.31 & .704 & 2.57 & .535 & 2.81 & .403 \\
\hline Role implication & 2.14 & .378 & 1.75 & .683 & 2.00 & .816 & 2.13 & .806 \\
\hline Co-construction & 1.71 & .756 & 1.88 & .719 & 1.86 & .690 & 1.44 & .512 \\
\hline Parental scaffolding & 1.86 & .900 & 1.63 & .500 & 1.57 & .535 & 1.88 & .342 \\
\hline Support & 2.29 & .756 & 2.31 & .602 & 2.29 & .488 & 2.25 & .577 \\
\hline Conflicts & 2.43 & .787 & 2.19 & .655 & 2.00 & .816 & 2.19 & .834 \\
\hline Involvement & 1.86 & .900 & 1.81 & .544 & 2.14 & .900 & 2.00 & .632 \\
\hline Self-regulation & 2.00 & .816 & 1.88 & .719 & 1.71 & .756 & 1.75 & .775 \\
\hline Interactive mistakes during activities & 1.86 & .690 & 1.63 & .719 & 1.29 & .488 & 1.38 & .719 \\
\hline Interactive mistakes during transitions & 2.29 & .951 & 1.94 & .574 & 2.29 & .488 & 2.50 & .516 \\
\hline Warmth & 1.86 & .900 & 1.81 & .750 & 1.57 & .535 & 1.50 & .730 \\
\hline Validation & 2.00 & .816 & 1.69 & .793 & 1.71 & .756 & 1.69 & .479 \\
\hline Authenticity & 2.57 & .787 & 2.88 & .342 & 2.57 & .535 & 2.81 & .403 \\
\hline Total global scores & 31.00 & 8.206 & 29.06 & 5.131 & 27.57 & 4.826 & 28.13 & 4.66 \\
\hline
\end{tabular}

$\mathrm{T} 0$, time of the diagnostic assessment; T12, after 12 months of treatment; SD, standard deviation. 
Using correction of Bonferroni Post-Hoc the only still significant variable was Interactive mistakes during activities. Looking at Table 3, we noticed that this variable presented a different change between group A and group B: within group A the variable decreased from $\mathrm{T} 0(\mathrm{M}=9.86$; $\mathrm{SD}=1.773)$ to $\mathrm{T} 12(\mathrm{M}=7.43 ; \mathrm{SD}=2.440)$ while in group $\mathrm{B}$ we noticed an increase of the same variable from $\mathrm{T} 0$ $(\mathrm{M}=7.31 ; \mathrm{SD}=2.358)$ to $\mathrm{T} 12(\mathrm{M}=9.06 ; \mathrm{SD}=2.235)$.

\section{Discussion}

This study presented the results of one-year pilot research evaluating the clinical effectiveness of an integrated treatment, characterized by psychotherapy for child/adolescent and parental support for the parents in addition to the assessment of family interactions. Although the research evaluating clinical effectiveness of integrated treatment in infant mental health deals with critical methodological and theoretical issues and the small size of the sample, it can be affirmed that this study sheds light on interesting results.

First of all, as regard the effectiveness of the integrated intervention on the child/adolescent psychopathological profile, measured throughout the CBCL (Achenbach \& Rescorla, 2001), we found a significant change in the clinical level of internalizing problems' symptomatology after one-year treatment.
Although preliminary, these results seem to be in line with literature evidences (Palmer et al., 2013; Gatta et al., 2015a) which show that patients with internalizing disorders seem to respond quicker and better to psychotherapeutic treatment than those with externalizing problems. Indeed, patients with externalizing problems seem more difficult to treat and to involve in research studies and, furthermore, it appears more difficult to build a working alliance with them (Midgley \& Kennedy, 2011).

On the other hand, Hemphill and Littlefield (2006) indicated that predictors of reductions in externalizing and internalizing behaviors following treatment were children's pre-existing levels of the above behavioral and emotional problems and a positive parent-child interaction. Therefore, it is recommended that future research, in light with the perspective of this study, should focus on the presence of any differences in the quality of interactive family dynamics both in the context of internalizing and externalizing child/adolescent groups of patients from the beginning of their engagement into treatment; it would be also of some help trying to detect whether such an aspect could be related with a drop in their symptomatology after the treatment itself. This data should be able to offer some additional information, aimed to set up a more structured intervention with families characterized by the presence of a strong connection between the intensity of child/ado-

Table 3. Mean and standard deviation of the sum scores of Lausanne Trilogue Play variables at the time of the diagnostic assessment and after 12 months of treatment divided into group $A(n=7)$ and group $B(n=16)$.

\begin{tabular}{|c|c|c|c|c|c|c|c|c|}
\hline \multirow[t]{3}{*}{ Sum score } & \multicolumn{4}{|c|}{ T0 } & \multicolumn{4}{|c|}{ T12 } \\
\hline & \multicolumn{2}{|c|}{ Group A } & \multicolumn{2}{|c|}{ Group B } & \multicolumn{2}{|c|}{ Group A } & \multicolumn{2}{|c|}{ Group B } \\
\hline & Mean & SD & Mean & SD & Mean & SD & Mean & SD \\
\hline Postures and gazes & 8.00 & 1.633 & 7.00 & 2.757 & 6.57 & 2.992 & 7.31 & 1.852 \\
\hline Inclusion of partners & 11.14 & 1.864 & 8.31 & 2.822 & 8.29 & 2.984 & 10.00 & 2.366 \\
\hline Role implication & 9.29 & 1.113 & 7.25 & 2.082 & 7.29 & 3.861 & 8.69 & 2.120 \\
\hline Co-construction & 7.57 & 2.760 & 6.50 & 2.582 & 5.57 & 2.992 & 5.94 & 1.879 \\
\hline Parental scaffolding & 8.43 & 2.878 & 6.38 & 2.500 & 5.86 & 3.024 & 7.06 & 1.914 \\
\hline Support & 9.14 & 2.193 & 7.81 & 2.316 & 7.57 & 3.309 & 8.06 & 2.323 \\
\hline Conflicts & 9.86 & 2.193 & 8.31 & 2.522 & 7.14 & 3.485 & 8.63 & 2.802 \\
\hline Involvement & 8.14 & 2.968 & 6.88 & 2.604 & 7.29 & 3.729 & 7.44 & 2.851 \\
\hline Self-regulation & 8.57 & 2.699 & 7.50 & 3.055 & 6.29 & 3.352 & 6.75 & 3.044 \\
\hline Interactive mistakes during activities & 7.00 & 2.309 & 6.19 & 2.639 & 5.14 & 2.734 & 6.38 & 2.473 \\
\hline Interactive mistakes during transitions & 9.86 & 1.773 & 7.31 & 2.358 & 7.43 & 2.440 & 9.06 & 2.235 \\
\hline Warmth & 7.71 & 2.984 & 6.44 & 3.010 & 5.57 & 2.992 & 5.81 & 2.664 \\
\hline Validation & 7.57 & 3.457 & 6.44 & 2.828 & 6.71 & 3.352 & 6.38 & 2.062 \\
\hline Authenticity & 10.43 & 2.507 & 9.81 & 2.455 & 8.43 & 3.735 & 10.19 & 2.257 \\
\hline Total sum scores & 129.71 & 27.5 & 107.94 & 31.28 & 95.14 & 42.49 & 107.69 & 27.36 \\
\hline
\end{tabular}

T0, time of the diagnostic assessment; T12, after 12 months of treatment; SD, standard deviation. 
lescent psychopathology and family peculiarities, noticed from the early stages of treatment.

However, the results obtained emphasize some limitations of the study and the need for a control group able to detect any influences of the maturation effect on the outcome.

With regards to the effectiveness of the use of the LTP we found statistical results partly confirming the importance of an integrated approach. Apparently, the abovementioned go in the opposite direction of our hypothesis: firstly, we did not find significant improvement in the quality of family interactive dynamics after one year of treatment; secondly, we noticed an improvement in the quality of family interactive dynamics only in some variables - discussed after - in the group without video-feedback intervention. Moreover, on the other side, we found a drop in the same family interactive dynamics within the group receiving video-feedback intervention.

In our very initial hypothesis, families who received video-feedback intervention would have presented a significant improvement in the quality of family interactive dynamics after one year of treatment. After the analysis, we thought to find out other variables that would have influenced the apparently strange association we found. First of all, it must be mentioned the interval time between each video-feedback session. Studies found in literature describe video-feedback applications every two weeks or once a month (Papousek \& Chuquisengo, 2006). In this preliminary study we applied video-feedback intervention only every six months. As a consequence, it is likely that, as video feedback was performed only once after six months from the beginning of our study, it might have not served enough an intense therapeutic alliance between family and the clinician, essential to determine a significant change in family interactive dynamics. These results emphasize the need for further studies on video-feedback procedure using a different methodology in order to detect the optimum frequency for this type of families. However, it is important to emphasize the value of this pilot study in introducing an innovative technique able to catch triadic interactions, never used before in the premises of the Infancy and Adolescence Family Unit; this study also gave way to the opportunity of using observations in working with parents through the technique of video-feedback.
Secondly, we know from a general qualitative study that the families belonging to the subgroup studied in this work showed particular clinical peculiarities (Gatta et al., 2015a, 2015b, 2015c). Analyzing the peculiarities of these families we have observed that families with no parental support present at the time of the take in charge better parental competences and lower level of adolescent psychopathology. This data is in line with the fact that after the psycho-diagnostic assessment the clinician decided to propose both parental support and adolescent take in charge to the families that present more limits (these families go to compose the target group of this study). It's interesting to notice that in the group where families have more resources from the beginning we found some effect of the video-feedback intervention on the quality of family interactive dynamics also after one year of treatment. It is possible to hypothesize that, given the limited initial resources in the families belonging to the group with parental support, it would take more time to observe some relevant effects of the clinical intervention and maybe it would be necessary to put in place a more structured intervention for families with more complex needs like the participants to this study. These hypothesis are supported by literature results (Tonge, Pullen Hughes \& Beaufoy, 2009) which found a significant reduction of depressive, social and attention symptoms but no significant results regarding the overall functioning of the family after one year of treatment. The authors explain these evidences by saying that adolescents turning up to the service were characterized by high levels of complexity of symptoms, comorbidity of multiple diagnoses and poor functioning, in addition to an impaired capacity to be in relationships mirroring also their difficulties within the family environment.

Thirdly, these results recommend a clinical intervention. A psychodynamic approach was proposed to the families both in the work with the child/adolescent and with his/her parents. From a clinical perspective it is well known that psychotherapy works more widely on a representative level while video-feedback intervention is active on a more practical and concrete sphere with the families.

As a consequence, it could be hypothesized that in families suffering more, and affected by a wider range of

Table 4. Mann-Whitney test of the sum score of Lausanne Trilogue Play variables between groups A and B.

\begin{tabular}{lccc}
\hline & U of Mann-Whitney & Z & Sign \\
\hline Inclusion of the partners & 18,000 & -2.567 & .010 \\
\hline Role implication & 25,000 & -2.096 & .039 \\
\hline Scaffolding & 21,500 & -2.321 & .018 \\
\hline Conflicts & 24,000 & -2.088 & .039 \\
\hline Interactive mistakes during transitions & 14,000 & -2.820 & .004 \\
\hline
\end{tabular}


clinical peculiarities (higher level of psychopathology, lower parental competences) a more concrete level of intervention, namely video-feedback, should be preceded by a softer approach to the family; in this way the latter would be more emotionally and mentally prepared to make a transition to a more representational level of work inferred from the observation of plain family interactions. Secondary to such a treatment, perhaps, it would be more likely to observe some improvement in the quality of family interactive dynamics after two years of intervention.

\section{Conclusions}

Highlighting the present results we can underline that something seems to change in the family interactive dynamics even though in a different way (increasing or decreasing) in the two subgroups. It seems relevant point out that two of the variables fluctuating in term of results regard parental competences. It is possible that clinical intervention might really have some effects although at the moment it is not possible to draw on certain assumptions in which direction and with how much intensity videofeedback intervention functions. This data should support the idea of the importance of the application of an integrated approach that involves the intervention with parents. Among parental support, video-feedback and the two of them run in parallel, which one is the best kind of intervention to be proposed to families is a matter still to be widely explored.

Nevertheless, some important limitations must be considered when interpreting the results of this study. Firstly, the study included a sample of families referred to a Neuropsychiatric Unit. More researches with larger and different types of samples coming from different services would be necessary. Secondly, it is important to point out that, provided a small sample size in proportion to the number of analyzed variables, its results should be considered as exploratory. Thirdly, as highlighted before, this study focuses on the effectiveness of treatment after one year. We assume that some initial effects of the clinical work will be visible after a longer period of time. It is relevant to take into account that, whilst LTP gives way to an understanding on the interactive level, the psychodynamic approach works on the representative levels of the family and such changes are difficult to process; therefore it is possible to assume that major qualitative changes in the quality of interactive dynamics will come with time.

\section{References}

Achenbach, T.M., \& Rescorla, L.A. (2001). Manual for the ASEBA school-age forms \& profiles. Burlington: University of Vermont, Research Center for Children Youth and Families.

Aliprandi, M., Pelanda, E., \& Senise, T. (1990). Psicoterapia breve di individuazione. La metodologia di Tommaso Senise nella consultazione con l'adolescente. Milano: Feltrinelli.
Armsden, G., Pecora, P.J., Payne, V.H., \& Szatkiewicz, J.P. (2000). Children placed in long-term foster care: an intake profile using the child behavior checklist/4-18. Journal of Emotional and Behavioral Disorders, 8(1), 49-64.

Ballabio, M., \& Sala, A.D. (2012). La tossicodipendenza in adolescenza. Il contributo del Lausanne Trilogue Play. In Simonelli A., Bighin M., \& De Palo F. (Eds.) Il Lausanne Trilogue Play. Modelli di ricerca e di intervento (pp. 279301). Milano: Raffaello Cortina.

Ballabio, M., Pantè, S., \& Destro, S. (2009). Tossicodipendenza in adolescenza. La trama delle interazioni familiari. Symposium Congresso Nazionale dell'Associazione Italiana di Psicologia (AIP). Chieti, Italy; 18-20 settembre 2009.

Bellamy, J.L., Gopalan, G., \& Traube, D.E. (2010). A national study of the impact of outpatient mental health services for children in long-term foster care. Clinical Child Psychology and Psychiatry, 15(4), 467-479.

Bighin, M., De Palo, F., \& Simonelli, A. (2011). Lo sviluppo delle interazioni madre-padre-bambino dalla gravidanza al nono mese attraverso il Lausanne Trilogue Play. Una replicazione in ambito italiano. Infanzia e Adolescenza, 10(3), 137-153.

Bonfiglio, S. (2009). La funzione genitoriale in adolescenza oggi. Adolescenza e Psicoanalisi, 4(2).

Carneiro, C., Corboz-Warnery, A., \& Fivaz-Depeursinge, E. (2006). The Prenatal Lausanne Trilogue Play: a new observational assessment tool of the prenatal coparenting alliance. Infant Mental Health Journal, 27(2), 207-228.

Cowan, C.P., Cowan, P.A., \& Barry, J. (2011). Couples' groups for parents of preschoolers: ten-year outcomes of a randomized trial. Journal of Family Psychology, 25(2), 240-250.

Cummings, E.M., Davies, P.T., \& Campbell, S.B. (2000). Developmental psychopathology and family process. New York: The Guilford Press.

Dazzi, N. (2006). Il dibattito contemporaneo sulla ricerca in psicoterapia. In Dazzi N., Lingiardi V., \& Colli A. (Eds.) La ricerca in psicoterapia. Modelli e strumenti (pp. 3-29). Milano: Raffaello Cortina.

De Coro, A., Andreassi, S., Mariani, R., Iberni, E., Crisafulli, V., \& Matarrese, A. (2010). La valutazione degli esiti e del processo nelle psicoterapie offerte dai Centri di Salute Mentale e da un Centro di Psicologia clinica universitario. Ricerca in Psicoterapia/Research in Psychotherapy: Psychopathology, Process and Outcome, 2(13), 125-146.

Fauber, R.L., \& Long, N. (1991). Children in context: the role of the family in child psychotherapy. Journal of Consulting and Clinical Psychology, 59(6), 813-820.

Favez, N., Frascarolo, F., Carneiro, C., Montfort, V., CorbozWarnery, A., \& Fivaz-Depeursinge, E. (2006). The development of the family alliance from pregnancy to toddlerhood and children outcomes at 18 months. Infant and Child Development, 15(1), 59-73.

Fivaz-Depeursinge, E., \& Corboz-Warnery, A. (1999). The Primary Triangle. A developmental systems view of fathers, mothers and infants. New York: Basic Books.

Gaggero, R. \& Orsini, S. (2002). Psicoterapia infantile: dai modelli teorici alla pratica clinica. Psichiatria dell'Infanzia e dell'adolescenza, 69, 531-540.

Gatta, M., Simonelli, A., Sudati, L., Sisti, M., Svanellini, L., Stucchi, ..., Battistella, P.A. (2015a). Emotional difficulties in adolescence: psychopathology and family interactions. International Neuropsychiatric Disease Journal, 4(1), 47-54.

Gatta, M., Simonelli, A., Svanellini, L., Sisti, M. \& Sudati, L. 
(in press-a). Preliminary adaptation of the family alliance assessment scales to the period of the adolescence. Book of Chapter, 7th International and 12th National Congress of Clinical Psychology. Sevilla, Spain; 14-16 November 2014.

Gatta, M., Sisti, M., Brunello, G., Sale, E., Simonelli, A., \& Battistella, P.A. (2014). Valutazione delle relazioni familiari nell'intervento psicomotorio con pre-adolescenti affetti da paralisi cerebrale. Giornale di Neuropsichiatria dell'Età Evolutiva, 34, 73-81.

Gatta, M., Sisti, M., Svanellini, L., Sudati, L., Chioccarello, M., Comis, I., \& Spoto, A. (2015b). Intergenerational transmission of the parental bond in adolescence: a case control study. International Neuropsychiatric Disease Journal, 5(1).

Gatta, M., Sudati, L., Sisti, M., Comis, I., Svanellini, L., Simonelli, A., \& Battistella, P.A. (2015c). Intergenerational transmission of attachment. Family interactive dynamics and psychopathology: what kind of relationship? International Neuropsychiatric Disease Journal, 4(2), 84-91.

Gatta, M., Svanellini, L., Sisti, M., Sudati, L., Stucchi, M., Fregna, R., ..., Battistella, P.A. (in press-b). Preliminary findings of the project: the Lausanne Trilogue Play as a psychodiagnostic and therapeutic tool for the neuropsychiatry unit- an innovative clinical experience with psychiatric children and adolescents. Book of Chapter, 7th International and 12th National Congress of Clinical Psychology. Sevilla, Spain; 14-16 November 2014.

Hedenbro, M., \& Rydelius, P.A. (2013). Early interaction between infants and their parents predicts social competence at the age of four. Acta Pcediatrica, 103(3), 268-274.

Hemphill, S.A., \& Littlefield, L. (2006). Child and family predictors of therapy outcome for children with behavioral and emotional problems. Child Psychiatry \& Human Development, 36(3), 329-349.

Jacobsen, S.L., McKinney, C.H., \& Holck, U. (2014). Effects of a dyadic music therapy intervention on parent-child interaction, parent stress, and parent-child relationship in families with emotionally neglected children: a randomized controlled trial. Journal of Music Therapy, 51(4), 310-332.

Lavanchy Scaiola, C., Favez, N., Tissot, H., \& Frascarolo, F. (2009). Family Alliance Assessment Scale (FAAS), version 6.3. Lausanne: Centre d'Etude de la Famille.

Leichsenring, F., Leweke, F., Klein, S., \& Steinert, C. (2015). The empirical status of psychodynamic psychotherapy - an update: bambi's alive and kicking. Psychoterapy and Psychosomatics, 84(3), 129-148.

Lenzo, V., Gargano, M.T., Mucciardi, M., Lo Verso, G., \& Quattropani, M.C. (2014). Clinical efficacy and therapeutic alliance in a time-limited group therapy for young adults. Research in Psychotherapy: Psychopathology, Process and Outcome, 17(1), 9-20.

Losso, R. (2000). Psicoanalisi della famiglia. Percorsi teorico clinici. Milano: Franco Angeli.

Mazzoni, S., Castellina, I., \& Veronesi, C. (2012). I disturbi dello sviluppo: una procedura multi metodo per l'assessment delle dinamiche familiari. In Simonelli A., Bighin M., \& De Palo F. (Eds.) Il Lausanne Trilogue Play. Modelli di ricerca e di intervento (pp. 279-301). Milano: Raffaello Cortina.

McHale, J.P. (2007). When infants grow up in multiperson relationship systems. Infant Mental Health Journal, 28(4), 370-392.

Midgley, N., \& Kennedy, E. (2011). Psychodynamic psychotherapy for children and adolescents: A critical review of the evidence base. Journal of Child Psychotherapy, 37(3), 232-260.

Montinari, G., \& Pelanda, E. (2012). La relazione adolescentadulti. Riflessioni psicoanalitiche ed esperienze cliniche. Roma: Il Pensiero Scientifico.

Novick, K.K., \& Novick, J. (2009). Il lavoro con i genitori. I migliori alleati nella psicoterapia del bambino e dell'adolescente. Milano: Franco Angeli.

Odhammar, F., Sundin, E.C., Jonson, M., \& Carlberg, G. (2011). Children in psychodynamic psychotherapy: changes in global functioning. Journal of Child Psychotherapy, 37(3), 261-279.

Palmer, R., Nascimento, L.N., \& Fonagy, P. (2013). The state of the evidence base for psychodynamic psychotherapy for children and adolescents. Child and Adolescent Psychiatric Clinics of North America, 22(2), 149-214.

Papousek, M., \& Chuquisengo, R. (2006). Integrative parent-infant psychotherapy for early regulatory and relationship disorders. Praxis Kinderpsycholog Kinderpsychiatrie, 55(4), 235-254.

Petech, E., Simonelli, A., \& Altoè, G. (2009). Interazioni triadiche, benessere della coppia e ruolo del padre nelle famiglie con bambini in età prescolare. Ricerche di psicologia, (1), 135-156. doi: 10.3280/RIP2009-001008

Sameroff, A.J., McDonough, S.C., \& Rosenblum, K.L. (2004). Il trattamento clinico della relazione genitore-bambino. Tr. it. Bologna: Il Mulino.

Shaffer, D., Fisher, P., Dulcan, M.K., Davies, M., Piacentini, J., Schwab-Stone, M.E., ..., Regier, D.A. (1996). The NIMH Diagnostic Interview Schedule for Children Version 2.3 (DISC-2.3): description, acceptability, prevalence rates, and performance in the MECA study. Methods for the epidemiology of child and adolescent mental disorders study. Journal of American Academy of Child and Adolescent Psychiatry, 35(7), 865-877.

Shaffer, D., Gould, M.S., Brasic, J., Ambrosini, P., Fisher, P., Bird, H., \& Alwahlia, S. (1983). A children's global assessment scale (CGAS). Archives of General Psychiatry, 40(11), $1228-1231$

Simonelli, A., Bighin, M., \& De Palo, F. (2012). Il Lausanne Trilogue Play. Modelli di ricerca e di intervento. Milano: Raffaello Cortina.

Simonelli, A., Fava Viziello, G.M., Bighin, M., De Palo, F., \& Petech, E. (2007). La transizione alla triade fra assunzione della genitorialità e riorganizzazione della coppia. Età Evolutiva, 86, 92-99.

Simonelli, A., Fava Viziello, G.M., Petech, E., Ballabio, M., \& Bisoni, E. (2009). Il Lausanne Trilogue Play: potenzialità diagnostiche e prospettive di intervento nella valutazione delle competenze interattive familiari. Infanzia e Adolescenza, 8(1), 1-12.

Simonelli, A., Sisti, M., Svanellini, L., Sudati, L., Fregna, R., Vellon, L., ..., Gatta, M. (2014). Is there any relationship between children and psychopathology and interactive family patterns? Infant Mental Health Journal Supplement, 35(3), 243.

Svanellini, L., Gatta, M., Sisti, M., Bubola, M., Bellotto, D., Simonelli, A., \& Battistella, P.A. (in press). Video feedback as a tool in parental support therapy for clinical family. Book of Chapter, 7th International and 12th National Congress of Clinical Psychology. Sevilla, Spain; 14-16 November 2014.

Thomas, R., \& Zimmer-Gembeck, M.J. (2007). Behavioral outcomes of parent-child interaction therapy and triple p-posi- 
tive parenting program: a review and meta-analysis. Journal of Abnormal Child Psychology, 35(3), 475-495.

Tonge, B.J., Pullen, J.M., Hughes, G.C., \& Beaufoy, J. (2009). Effectiveness of psychoanalytic psychotherapy for adolescents with serious mental illness: 12 month naturalistic follow-up study. Australian and New Zealand Journal of Psychiatry, 43(5), 467-475.
Trautmann-Villalba, P., Gschwendt, M., Schmidt, M.H., \& Laucht, M. (2006). Father-infant interaction patterns as precursors of children's later externalizing behavior problems. A longitudinal study over 11 years. European Archives of Psychiatry \& Clinical Neuroscience, 256(6), 344-349.

Vallino, D. (2009). Psicoanalisi con genitori e bambini. Roma: Borla. 